really sharp keratome are only found among the instruments of the ophthalmic surgeon or eye hospital. The operations described above can be done with instruments in everyday use-scalpel and scissors are easy to come by. The hook, although exceedingly useful, can be replaced by a stitch, or the incision can be done with fixation on the internal rectus. Also the work of the de Weckers can be done with ordinary scissors.

\title{
REFERENCES
}

GAYET (1884).-Bull. Soc. frang. d'Ophtal., 44.

CzERMAK (1901).-Nagels Jahrb., 32, 329.

Elschnig.(1928).-Klin. Monatsbl. $f$. Augenheilk., 80, 382.

SALZMAN N (1930).-Zeitschr. $f$. Augenheilk., 72, 127.

WEEKERS, L. (1931).-Arch. d:Ophtal., 48, 593.

(1948).-Bull. Soc. belge d'Ophtal., 268.

\section{ON THE USE OF AMNIOTIC MEMBRANE}

$$
\text { BY }
$$

C. DANSEy-Browning

LONDON

Captain C., aged 30 years. The benign melanoma conjunctivae situated at the external canthus of the left eye, had recentiy shown signs of extension. Fig. 1, August 19, 1948. The growth was

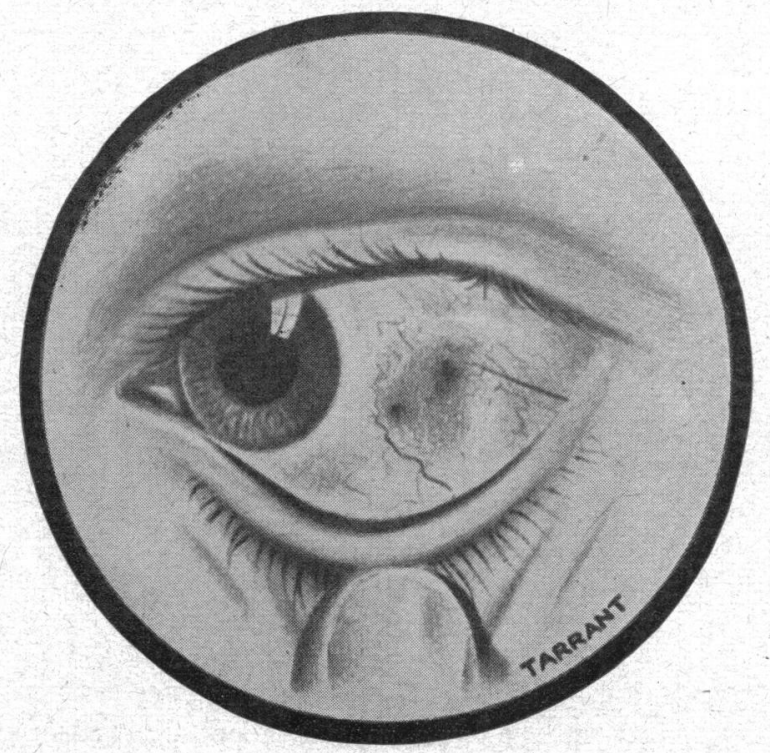

FIG. 1. 


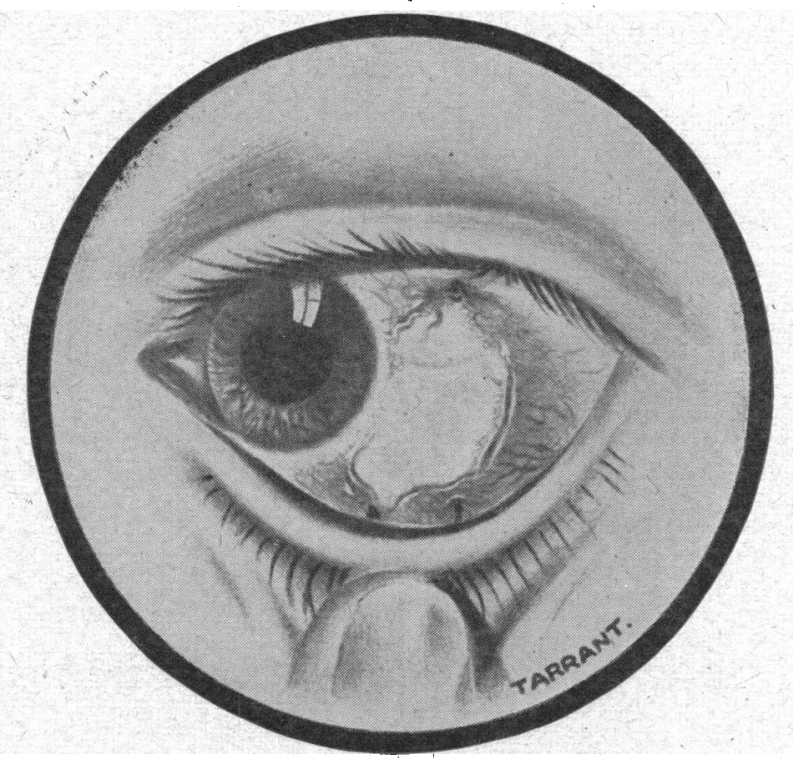

FIG. 2.

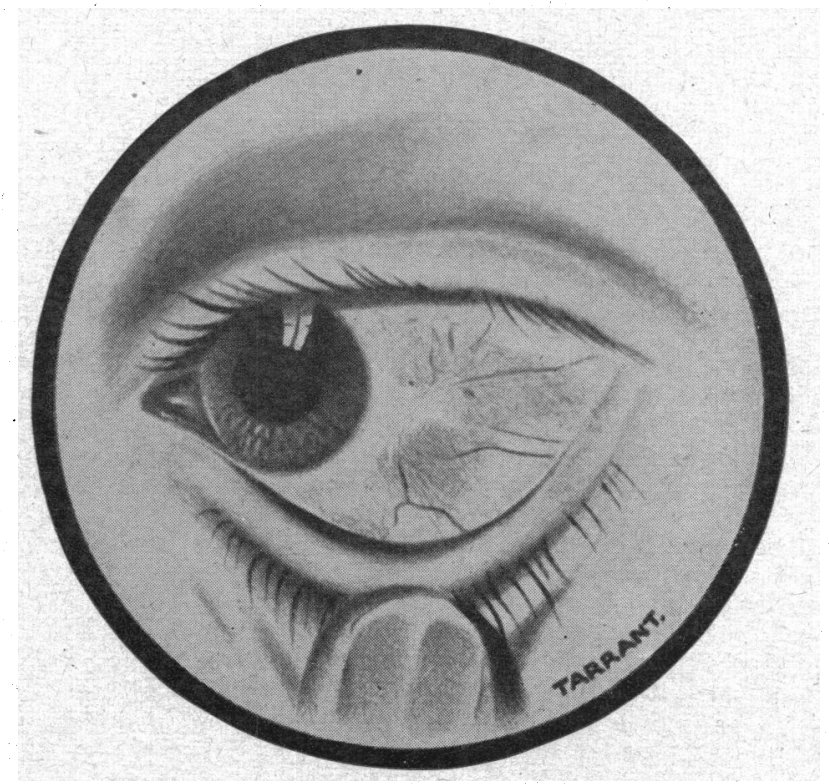

Fig. 3. 
excised on August 20,1948, and a piece of London Hospital sterile amniotic membrane (Morley's process-fat-free) of the same size as the raw area, was sutured into position.

The appearance of the eye some four days after the operation is shown in Fig. 2, August 24, 1948, The appearance of the conjunctiva a month after operation is shown in Fig. 3, September 29, 1948.

It is felt that these representations of the appearance of the eye during the regeneration period of the conjunctiva are of interest. Also they indicate a possible use for amniotic membrane in the early treatment of ophthalmic wounds in war-time, particularly in the mobile ophthalmic units in forward areas.

\title{
UNUSUAL OCULAR FOREIGN BODY
}

\author{
BY \\ Nirmal Kumar Ghose \\ Calcutta
}

VARIOUS authors have reported the occurrence of different types of intra-ocular worms, but the occurrence of a snail in the eye must be of extreme rarity, if indeed it has ever been known.

\section{Case Report}

K.R.M.. a 16-year old male, came on October 1, 1948, with a history of irritability in the left eye together with deep left orbital aching of one week's duration. These symptoms began about half an-hour after washing his face in a pond.

Examination revealed superficial punctate keratitis and the inferior palpebral conjunctiva was congested. There were large follicles in rows upon the lower fornix. While the lower fornix was being examined a small snail emerged apex first from under the conjunctiva, and started moving across the palpebral conjunctiva. It was picked up by a swab-stick, and preserved in formalin.

On more detailed examination corneal sensation was found lost and the pre-auricular gland enlarged. Slit-lamp examination showed typical sub-epithelial infiltration and blebs.

The deep boring pain passed away about two minutes after tbe emergence of the snait. The keratitis cleared up completely with dark glasses, normal saline, Ung. Atropine 1 per cent., and Sterodin-2 c.c. every other day, and by October 12, 1948, he was cured.

The snail was taken to the Department of Helminthology in thc School of Tropical Medicine, and was identified as a young Vivipara Bengalensis,

The size of the snail is vertically apex to base one mm., and horizontally $2 \mathrm{~mm}$. I was told that a week earlier the size would have been no larger than a grain of sand. 